\title{
CARCINOMA DE CÉLULAS ESCAMOSAS ESOFÁGICO EM UMA GALINHA DOMÉSTICA
}

\author{
ZAMBONI, Rosimeri ${ }^{1}$; \\ SCHEID, Haide Valeska ${ }^{1}$; \\ HUGEN, Gustavo ${ }^{2}$; \\ LOBO, Raulene Rodrigues ${ }^{1}$; \\ MARCOLONGO-PEREIRA, Clairton ${ }^{3}$; \\ VARGAS, Gilberto D'Ávila ${ }^{4}$; \\ SALLIS, Eliza Simone Viégas ${ }^{5}$.
}

${ }^{1}$ Pós-Graduanda, Programa de Pós-Graduação em Veterinária, UFPEL; ${ }^{2}$ Pós-Graduando, Programa de PósGraduação em Ciência Animal, UDESC; ${ }^{3}$ Professor, Faculdade de Veterinária, UNESC/ES; ${ }^{4}$ Professor, Departamento de Veterinária Preventiva, Faculdade de Veterinária, UFPEL; ${ }^{5}$ Professora, Departamento de Patologia Animal, Faculdade de Veterinária, UFPEL.

\section{RESUMO}

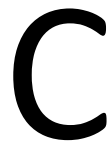

arcinoma de células escamosas (CCE) foi diagnosticado na mucosa esofágica de uma galinha doméstica (Gallus gallus domesticus), fêmea, adulta, criada de forma extensiva. Na necropsia foi observada uma massa no esôfago. Macroscopicamente era uma lesão firme, de superfície irregular que obstruía o lúmen do órgão. No exame histopatológico da lesão do esôfago evidenciou-se neoplasia infiltrativa e não encapsulada de células epiteliais escamosas. As células eram arranjadas em cordões e trabéculas, por vezes formando ninhos, nos quais havia estruturas eosinofílicas concentricamente laminadas (pérolas de queratina), sustentadas por moderada quantidade de estroma fibrovascular. $\mathrm{O}$ CCE não é comumente diagnosticado no esôfago de aves. Muitas aves com dificuldade de deglutição e emaciação morrem e são descartadas sem a realização de um diagnóstico confirmatório da causa da morte. Alerta-se para necessidade da realização do exame histopatológico para o diagnóstico definitivo desses casos.

Palavras-chave: Ave. Carcinoma. Esôfago. Gallus gallus domesticus. 


\section{INTRODUÇÃO}

Carcinoma de células escamosas (CCE) é um tumor maligno das células da epiderme que apresentam diferenciação de queratinócitos. Diversos fatores têm sido associados ao desenvolvimento do carcinoma nos animais domésticos, incluindo a exposição prolongada à radiação ultravioleta, a falta de pigmentação na epiderme, agentes químicos e a infecção pelo papilomavírus (CHIN; BARR, 1990; VÁZQUEZ et al., 2003).

Nos animais domésticos o CCE ocorre comumente em felinos, caninos, bovinos e equinos, sem predileção por espécie, sexo e raça (CARDONA et al., 1992). O CCE tem sido descrito, também, em várias espécies de aves, incluindo os galináceos e pássaros (MALKA et al., 2005). A forma mais frequente de carcinoma de células escamosas observada em aves é a cutânea, e poucos são os relatos desta neoplasia afetando a cavidade oral e o trato gastrintestinal (ANDERSON; STEINBERG, 1989; MALKA et al., 2005; VÁZQUEZ et al., 2003).

No Brasil, até o momento, não há descrição dessa neoplasia na cavidade oral de aves domésticas. O objetivo deste trabalho foi descrever a ocorrência de carcinoma de células escamosas no esôfago de uma ave doméstica no sul do Rio Grande do Sul.

\section{RELATO DE CASO}

Foi recebido no Laboratório Regional de Diagnóstico (LRD) da Faculdade de Veterinária da Universidade Federal de Pelotas (LRD/UFPEL), uma ave adulta (Gallus gallus domesticus), proveniente de uma propriedade localizada no município de Pelotas, Rio Grande do Sul, apresentando emagrecimento progressivo, edema de barbela e dificuldade de deglutição. $\mathrm{Na}$ necropsia fragmentos de todos os órgãos, incluindo o sistema nervoso central, foram coletados e fixados em formalina $10 \%$, processados rotineiramente e corados com hematoxilina e eosina (HE).

\section{RESULTADOS E DISCUSSÃO}

A galinha era criada extensivamente, com outras aves, para a produção de ovos, com alimentação fundamentalmente à base de milho. No exame clínico do animal observou-se uma massa na região do esôfago, que dificultava a deglutição. Macroscopicamente observou-se emaciação do cadáver e na abertura do trato digestório havia uma massa 
caseosa e amarelada que protruía para a luz do órgão (Figura 1A). A massa apresentava superfície irregular, firme, com aproximadamente $2 \mathrm{~cm}$ de diâmetro e estava aderida na porção inicial do esôfago, obstruindo a luz do órgão.

Histologicamente a massa era infiltrativa, não encapsulada e mal delimitada, que se estendia da mucosa para a submucosa. As células eram poligonais, arranjadas em cordões e trabéculas, por vezes formando ninhos, nos quais havia estruturas eosinofílicas concentricamente laminadas (pérolas de queratina), sustentadas por moderada quantidade de estroma fibrovascular (Figura 1B). As células neoplásicas possuíam bordos citoplasmáticos variavelmente distintos com citoplasma abundante eosinofílico. Os núcleos eram irregularmente redondos ou ovais com cromatina finamente pontilhada e múltiplos nucléolos evidentes. Havia, ainda, células disqueratóticas e células com dois ou três núcleos. A taxa de mitose por campo de maior aumento era de duas figuras por campo. Havia marcada anisocariose e anisocitose. Nas áreas adjacentes ao tumor havia, ainda, acentuado infiltrado de plasmócitos, linfócitos e alguns heterófilos.
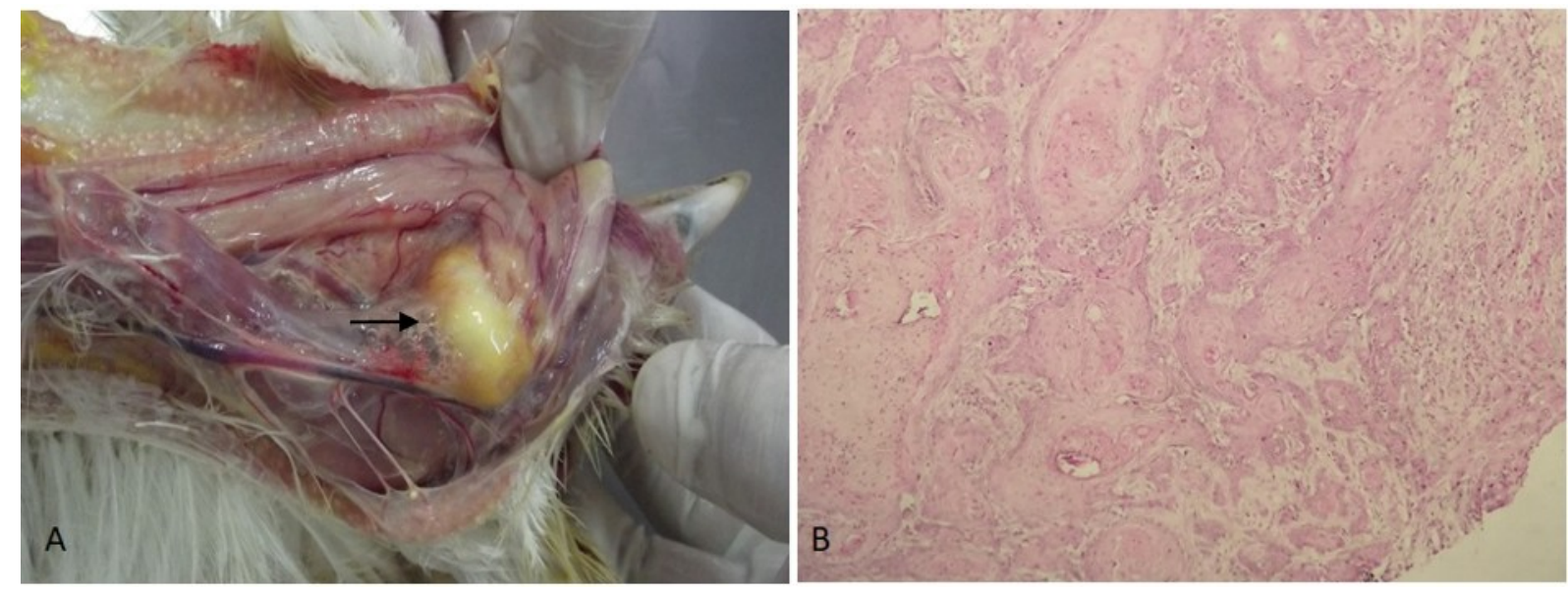

Figura 1 - Carcinoma de células escamosas. (A) Esôfago, verifica-se uma massa caseosa e amarelada (seta). (B) Histopatologia do tumor mostrado em A. Observam-se ninhos de células escamosas de citoplasma abundante, circundados por reação desmoplásica e células inflamatórias. No centro dos ninhos observa-se ceratina produzida pelas células neoplásicas. HE, obj. 20x.

No presente relato o diagnóstico de carcinoma de células escamosas esofágico foi realizado com base nas lesões macroscópicas e microscópicas características da neoplasia. A ocorrência de CCE na mucosa oral e esofágica é relatada com mais frequência em cães e 
gatos, mas rara em outros animais domésticos (RUBIO; LIU, 1989). Esse neoplasma tem sido diagnosticado em aves exóticas e silvestres afetando a mucosa oral, orofaringe e esôfago (CHIN; BARR, 1990).

O carcinoma de células ocorreu em uma ave adulta, como o observado em outros relatos da enfermidade. Em galinhas, geralmente são observados casos isolados de CCE esofágico em aves adultas e idosas e raramente em frangos jovens (FILGUEIRA; REIS, 2009; VÁZQUEZ et al., 2003). Fatores como exposição à radiação ultravioleta e infecções por vírus têm sido apontados como causa de neoplasias em animais domésticos (CHIN; BARR, 1990; VÁZQUEZ et al., 2003). Em aves, os irritantes químicos podem representar um importante papel na gênese do CCE, em comparação à radiação solar, bem como, a infecção por retrovírus (VÁZQUEZ et al., 2003). Em um surto de CCE em galinhas na China, apesar da causa não ter sido determinada, havia fortes indícios que um agente químico estava relacionado com o surgimento dos tumores nos animais (RUBIO; LIU, 1989).

Agentes químicos como nitroimidazóis e nitrofuranos, usados na prevenção de infecções por protozoários na avicultura, têm sido implicados como possíveis carcinógenos (DOLKA et al., 2015). Não foi relatada a utilização desses medicamentos nas aves da propriedade, porém não foi possível descartar a participação desses agentes ou de outras substâncias no desenvolvimento desta neoplasia.

O diagnóstico do CCE em galinhas é raro, entretanto, torna-se relevante no diagnóstico diferencial de outras enfermidades que causem lesões na região da orofaringe e esôfago das aves, como granulomas bacterianos e fúngicos, que poderiam acarretar prejuízos econômicos mais importantes para os criadores.

\section{CONCLUSÃO}

Alerta-se para a necessidade do exame histopatológico para o diagnóstico definitivo de CCE. Aves com dificuldade de deglutição e emaciação, geralmente morrem e são descartadas sem a realização de um diagnóstico confirmatório da causa da morte. As lesões histológicas são características nesta neoplasia e possibilitam descartar enfermidades infecciosas. 


\title{
ESOPHAGEAL SQUAMOUS CELL CARCINOMA IN A DOMESTIC CHICKEN
}

\begin{abstract}
quamous cell carcinoma (SCC) was diagnosed in the esophagic mucosa in a backyard hen, (Gallus gallus domesticus). At the necropsy, an esophageal mass was observed. Grossly the lesion was firm, with irregular surface and obliterated the organ lumen. Histologically, a non-encapsulated infiltrative epithelial neoplasm was observed. The cells were arranged in chords and trabeculae, sometimes forming nests, within concentric eosinophilic laminated structures (keratin pearls). SCC is not usually diagnosed in chicken esophagus. Many birds with swallowing difficulty and progressive weight loss die and are discarded without a confirmatory diagnosis. This case highlights the importance of histopathological examination for a definitive diagnosis of those cases.
\end{abstract}

Keywords: Poultry. Carcinoma. Esophagus. Gallus gallus domesticus.

\section{CARCINOMA DE CÉLULAS ESCAMOSAS ESOFÁGICAS EN UNA GALLINA DOMÉSTICA}

\section{RESUMEN}

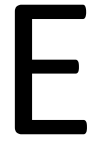
I carcinoma de células escamosas (CCE) fue diagnosticado en la mucosa esofágica de una gallina doméstica (Gallus gallus domesticus), hembra, adulta criada de forma extensiva. En la necropsia se observó una masa en el esófago. Macroscópicamente era una lesión firme, de superficie irregular que obstruía el lumen del órgano. En el examen histopatológico de la lesión del esófago se evidenció neoplasia infiltrativa y no encapsulada de células epiteliales escamosas. Las células estaban arregladas en cordones y trabéculas, a veces formando nidos, en los que había estructuras eosinofílicas concéntricas y laminadas (perlas de queratina), sostenidas por moderada cantidad de estroma fibrovascular. EI CCE no se suele diagnosticar en el esófago de aves. Muchas aves con dificultad de deglución y emaciación mueren y son descartadas sin la realización de un diagnóstico confirmatorio de la causa de la muerte. Se resalta la necesidad de la realización del examen histopatológico para el diagnóstico definitivo de estos casos.

Palabras clave: Ave. Carcinoma. Esófago. Gallus gallus domesticus. 


\section{REFERÊNCIAS}

ANDERSON, W. I.; STEINBERG, H. Primary glossal squamous-cell carcinoma in a Spanish Cochin hen. Avian Diseases, v. 33, n. 4, p. 827-828, 1989.

CARDONA, C. J.; BICKFORD, A. A.; EMANUELSON, K. Squamous-cell carcinoma on the legs of an Aracauna chicken. Avian Diseases, v. 36, n. 2, p. 474-479, 1992.

CHIN, R. P.; BARR, B. C. Squamous-cell carcinoma of the pharyngeal cavity in a Jersey Black Giant Rooster. Avian Diseases, v. 34, n. 3, p. 775-778, 1990.

DOLKA, B.; ŻBIKOWSKI, A.; DOLKA, I.; SZELESZCZUK, P. Histomonosis - an existing problem in chicken flocks in Poland. Veterinary Research Communications, v. 39, n. 3, p. 189-195, 2015.

FILGUEIRA, K. D.; REIS, P. F. C. C. Relato de caso: carcinoma dérmico de células escamosas em galo (Gallus gallus domesticus) geriátrico. Ciência Animal Brasileira, v. 10, n. 3, p. 9971001, 2009.

MALKA, S.; KEIRSTEAD, N. D.; GANCZ, A. Y.; TAYLOR, W. M.; SMITH, D. A. Ingluvial squamous cell carcinoma in a geriatric cockatiel (Nymphicus hollandicus). Journal of Avian Medicine and Surgery, v. 19, n. 3, p. 234-239, 2005.

RUBIO, C. A.; LIU, F. S. Spontaneous squamous carcinoma of the esophagus in chickens. Cancer, v. 64, n. 12, p. 2511-2514, 1989.

VÁZQUEZ, S.; QUIROGA, M. I.; ALEMAÑ, N.; GARCÍA, J. C.; LÓPEZ-PEÑA, M.; NIETO, J. M. Squamous cell carcinoma of the oropharynx and esophagus in Japanese Bantam Rooster. Avian Diseases, v. 47, n. 1, p. 215-217, 2003. 